\title{
Delayed anaphylaxis following propofol infusion in unknown egg allergic patient
}

\author{
Laoutid $\mathbf{J}^{1}$, Bibiche $\mathrm{L}^{2}$, Jbili $\mathrm{N}^{3}$, Chkoura $\mathrm{K}^{4}$, Hachimi $\mathrm{MA}^{5}$, Africha $\mathrm{T}^{6}$ \\ ${ }^{1}$ Dr. Jaoaud Laoutid, ${ }^{2}$ Dr. Lotfi Bibiche, ${ }^{3}$ Nabil Jbili, ${ }^{4}$ Khalid Chkoura, ${ }^{5}$ Moulay Ahmed Hachimi, all authors are \\ affiliated with Department of Anesthesiology and Critical Care, Military Hospital Moulay Ismail, Meknes, Morocco. \\ Faculty of Medicine and Pharmacy, Unviersity Sidi Mohamed Ben Abdellah, Fes, Morocco. ${ }^{6}$ Africha T, affiliated with \\ Department of Radiology, Military Hospital Moulay Ismail, Meknes, Morocco. Faculty of Medicine and Pharmacy, \\ Unviersity Sidi Mohamed Ben Abdellah, Fes, Morocco.
}

Address for Correspondence: Dr Jaouad Laoutid, Military Hospital Moulay Ismail, Meknes, Morocco. Email : jaouadl@hotmail.com

\begin{abstract}
We report a case of anaphylaxis that occurs more than one hour after propofol administration for colonoscopy. The patient did not reveal his allergy to egg in the preoperative evaluation. Administration of propofol to patient with egg allergy should be avoided.
\end{abstract}

Key word: Delayed anaphylaxis, propofol, egg allergy

\section{Introduction}

Incidence of allergic reaction during anesthesia is in the range of 1:10,000 to 1:20,000 [1]. As for drugs involved in perioperative anaphylaxis, muscle relaxant represented $69.2 \%$ of the incidence, while hypnotic was $3.7 \%$ [1]. Delayed anaphylaxis after propofol infusion during anesthesia is rarely reported. We report anaphylaxis appearing an hour and a half after exposure in patient under long-term corticosteroids and unknown egg allergy. The delay of apparition of anaphylaxis is probably due to corticosteroids taken by patient. Following this case report, we highlight the importance of asking for egg allergy before any propofol infusion.

\section{Case Report}

We report a case of a man 45 years old, $1.75 \mathrm{~m}$ for $80 \mathrm{Kg} \mathrm{BMI}=26 \mathrm{k} / \mathrm{m} 2$ presented for colonoscopy for colonic transit disorder, no allergy was reported in the patient file and he was under $10 \mathrm{mg}$ prednisolone daily for chronic rheumatism. His heart rate was $80 / \mathrm{min}$, and $\mathrm{BP} 120 / 70 \mathrm{mmHg}$ pulse oximetry at $98 \%$.

Intravenous access was secured with $18 \mathrm{G}$ catheter. Oxygen supplementation by facial mask and the induction was started by propofol with initial dose at $70 \mathrm{mg}$ then bolus reinjections (total dose $=200 \mathrm{mg}$ ). No anesthetic incident was noted and the patient's respiratory and hemodynamic values remained stable.

The colonoscopy was performed without technic difficulties during 25 minutes. The patient fully conscious with normal blood pressure was discharged from hospital 30 minutes after the end of procedure. One hour later the patient was admitted at the emergency department reporting asthenia and fever, examination revealed hyperthermia at $40^{\circ} \mathrm{C}$, cutaneous rash, hypotension at $89 / 45 \mathrm{mmHg}$ and heart rate at 110/min. Abdomen examination showed no abdominal guarding or abdominal wall rigidity. Respiratory examination fount no wheezing and Chest X-ray showed no pneumoperitoneum. biological exam shows leukocytosis at 21.000/mm3.

Manuscript received: $8^{\text {th }}$ March 2017

Reviewed: $17^{\text {th }}$ March 2017

Author Corrected: $26^{\text {th }}$ March 2017

Accepted for Publication: $31^{\text {st }}$ March 2017 


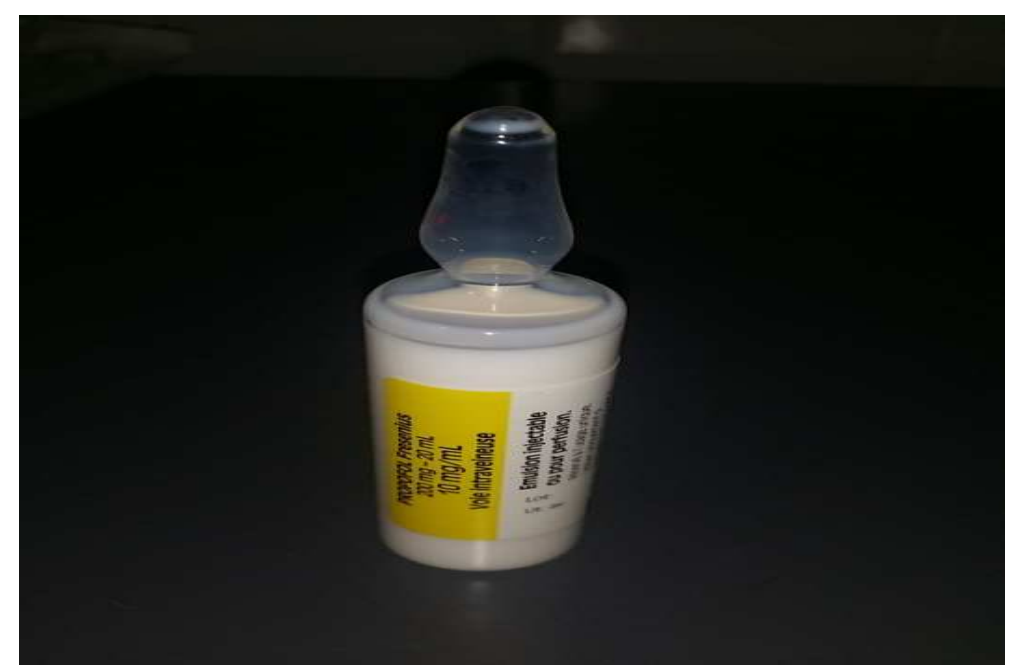

Fig-1: Propofol used for the patient

Asking for allergy the patient reported allergy to egg and avocado that was not revealed in the preoperative evaluation. The patient was admitted to the ICU, hemodynamic parameters improved after $1000 \mathrm{ml}$ of Saline flash infusion, $120 \mathrm{mg}$ of methylprednisolone and paracetamol $1 \mathrm{~g}$ administration. There was no need to use epinephrine and the patient remained stable during observation and he was discharged from ICU after 24 hours with ordonnance of $60 \mathrm{mg}$ prednisolone daily for 5 days. He was sent to allergology for further investigations.

\section{Discussion}

Propofol (2,6-diisopropylphenol) is more likely than other drugs used for induction of anesthesia to cause an allergic reaction, and $1.2 \%$ of cases of perioperative anaphylactic shock were attributable to propofol [2].

Contraindications to the use of propofol include allergies to generic or brand-name propofol and its emulsion; eggs or egg products; soybeans, soybean oil, or soy products; and glycerol [2,3]. Because people who are allergic to eggs are thought to be allergic to egg protein or albumin, not lecithin (the egg phosphatides which are present in the 'Diprivan' emulsion) [4]. There is some disagreement about whether egg allergy is a contraindication to propofol administration [5,6]. In one small study of 25 patients, none reacted to a skin-prick test using propofol [2]. The study's authors contend that egg-allergic patients are not highly susceptible to anaphylactic reactions to propofol [5]. A study by Baines et al demonstrated that the administration of propofol in patients with known allergy to egg was probably safe; however, it should not be given to patients with history of egg anaphylaxis [7].

Patients with allergy to eggs do not usually know to which component of the egg they are allergic. For this reason, some anesthesia care providers choose to administer propofol to a patient with a stated egg allergy while others prefer to administer a different medication to ensure patient safety.

The decision to administer propofol remains the discretion of the anesthesia care provider after he or she has performed a thorough risk-benefit assessment. The perioperative nurse should question the patient about egg and other food allergies, however, and ensure that all surgical team members should be aware of the information.

Early signs of an adverse reaction to propofol include a significant drop in blood pressure or cardiovascular depression, apnea, airway obstruction, and oxygen desaturation [3]. it occurs instantly or few minutes after propofol administration [5]. In our case it appeared more than one hour after, may be because of the corticosteroid medication that the patient was taking.

In our preoperative assessment tool, only medication allergy is noted. Simply asking patients about medication allergies is not enough; patients must be asked about food allergies as well, because they often do not relate food allergies to anesthesia or surgical contraindications [8]. After this case, we separated the allergy questionnaire into two subgroups: allergy to medication and food. 


\section{Conclusion}

Asking for food allergy is important in the preoperative evaluation, avoiding propofol infusion is better safe in patient reporting egg allergy, in order to prevent any anaphylactic reaction that may be delayed after propofol administration.

\section{Funding: Nil, Conflict of interest: None \\ Permission of IRB: Yes \\ Ethical approval: Not required.}

\section{References}

1. Dewachter P, Mouton-Faivre C, Emala CW. Anaphylaxis and anesthesia: controversies and new insights. Anesthesiology. 2009 Nov; 111 (5): 1141-50. doi: 10. 1097/ALN.0b013e3181bbd443.

2. Gangineni K, Scase AE, Fearn J. Propofol and peanut allergy. Anaesthesia. 2007 Nov;62(11):1191.
3. Sampson HA, Cooke SK. Food allergy and the potential allergenicity-antigenicity of microparticulated egg and cow's milk proteins. J Am Coll Nutr. 1990 Aug; 9 (4): 410-7.

4. Hepner DL, Castells MC. Anaphylaxis during the perioperative period. Anesth Analg. 2003 Nov;97 (5):1381-95.

5. Tashkandi J. My patient is allergic to eggs, can i use propofol? A case report and review. Saudi J Anaesth. 2010 Sep; 4(3):207-8. doi: 10.4103/1658-354X.71581.

6. Murphy A, Campbell DE, Baines D, Mehr S. Allergic reactions to propofol in egg-allergic children. Anesth Analg. 2011 Jul; 113(1):140-4. doi: 10.1213/ ANE. 0b013e31821b450f. Epub 2011 Apr 5.

7. Cochico SG. Propofol allergy: assessing for patient risks. AORN J. 2012 Oct;96(4):398-405; quiz 406-8. doi: 10.1016/j.aorn.2012.07.009.

\section{How to cite this article?}

Laoutid J, Bibiche L, Jbili N, Chkoura K, Hachimi MA, Africha T. Delayed anaphylaxis following propofol infusion in unknown egg allergic patient. Int J Med Res Rev 2017;5(03):368-370 doi:10.17511/ijmrr. 2017.i03.25. 